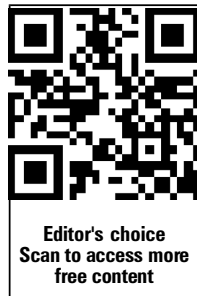

${ }^{1}$ Specialty Trainee 3 in Community Sexual and Reproductive Health, Newcastle Hospitals, Community Health, New Croft Centre, Newcastle upon Tyne, UK

${ }^{2}$ Consultant in Community Gynaecology and Reproductive Healthcare, Newcastle Hospitals, Community Health, New Croft Centre, Newcastle upon Tyne, UK

\section{Correspondence to}

Dr Diana Mansour, Newcastle Hospitals, Community Health, New Croft Centre, Market Street (East), Newcastle upon Tyne NE1 6ND, UK; diana.mansour@nuth.nhs.uk

Received 9 July 2013 Revised 31 July 2013 Accepted 1 August 2013
To cite: Percy L, Mansour D. J Fam Plann Reprod Health Care 2013:39:237-240.

\title{
Tailoring oral contraceptive pills to meet the needs of women
}

Laura Percy, ${ }^{1}$ Diana Mansour ${ }^{2}$

\section{BACKGROUND}

The combined oral contractive pill (COC) has been available for over 50 years but are we providing women with the regimens they want? As far back as 1977 , Louden et $a{ }^{1}{ }^{1}$ reported the use of 84 active pills with a 7-day break to free women from monthly periods, yet menstrual manipulation is underused today. So why do we have a 21/7 regimen for pill-taking?

\section{A BRIEF HISTORY}

When oral contraceptives were first developed, though the pioneering work of George Pincus, Carl Djerassi, Frank Carlton and John Rock, the presence of seven pill-free days allowed a withdrawal bleed that mimicked the natural cycle. The aim of this was to make a novel concept more acceptable. Dr Rock stated the 21/7 regimen was a "morally permissible variant of the rhythm method", 2 which was very important for the USA in the 1950s where birth control was illegal. Having a withdrawal bleed also gave women reassurance that they were not pregnant. The decision to adopt this approach was therefore social rather than physiological.

Acceptance of modern-day hormonal contraceptives has increased over time. Many women no longer wish to bleed each month and request 'an absence of withdrawal bleeds' to fit in with their busy lives. This has become possible with ethinylestradiol (EE) dose reduction and the introduction of new progestogens in novel COC regimens. Lowering the dose of synthetic estrogen means that the total intake of hormones is less with $20 \mu \mathrm{g}$ pills taken continuously when compared to $30 \mu \mathrm{g}$ pills taken with the traditional 7-day hormone break each month. When low-dose estrogen is combined with newer highly selective progestogens good cycle control results, making these hormones ideal partners for flexible extended regimens.
In the 1980s, tricycling of pills (putting three packets of COCs together followed by a 7-day break) became more commonplace but, despite Seasonale ${ }^{\circledR}$ [containing $30 \mu \mathrm{g}$ EE and $150 \mu \mathrm{g}$ levonorgestrel (LNG) with 84 active and seven placebo tablets] being available in the USA since 2003, the UK still does not have a licensed preparation. The 1990s and 2000s saw the introduction of pills with a reduced or no hormone-free interval. The first was Mircette ${ }^{\circledR}$ available in the USA since 1998 (containing $20 \mu \mathrm{g}$ EE and $150 \mu \mathrm{g}$ desogestrel for 21 days plus 5 days of $10 \mu \mathrm{g} \mathrm{EE}$ ), which has a 2-day hormone-free interval. Several products available in a number of developed countries have a 24/4 regimen such as Yaz ${ }^{\circledR}[20 \mu \mathrm{g}$ EE and $3 \mathrm{mg}$ drospirenone (DRSP)] and Loestrin $24 \mathrm{Fe}^{\circledR}(20 \mu \mathrm{g}$ $\mathrm{EE}$ and $1 \mathrm{mg}$ norethindrone acetate). In 2007, Lybrel ${ }^{\circledR}$, the first continuous pill containing $20 \mu \mathrm{g} \mathrm{EE}$ and $90 \mu \mathrm{g}$ LNG, was approved for use in the USA. However, it was not until Qlaira ${ }^{\circledR}$ (26 active pills with two containing $3 \mathrm{mg}$ estradiol valerate, five with $2 \mathrm{mg}$ estradiol valerate and $2 \mathrm{mg}$ dienogest, 17 with $2 \mathrm{mg}$ estradiol valerate and $3 \mathrm{mg}$ dienogest and a further two pills containing $1 \mathrm{mg}$ estradiol valerate together with two placebo tablets) in 2009 and Zoely ${ }^{\circledR} \quad(1.5 \mathrm{mg}$ estradiol and $2.5 \mathrm{mg}$ nomegestrol acetate with 24 active and four placebo pills) in 2013 that pills with shortened pill-free intervals became available in the UK.

With few available licensed preparations it is understandable that clinicians and users are hesitant about trying 'no-bleed or reduced-bleed' regimens. This year sees the global launch of Flexyess ${ }^{\circledR}$, which contains $3 \mathrm{mg}$ DRSP and $20 \mu \mathrm{g}$ EE. It is licensed as a 'flexible extended' cycle oral contraceptive taken for between 24 and 120 days with a 4-day pill free interval. To facilitate the use of this new product a Clyk ${ }^{\mathrm{TM}}$ dispenser has been developed. This hand-held device dispenses the pill, has an alarm to remind the woman to take her pill, 
provides advice relating to missed pills, and guides the user through their 4-day pill-free interval. ${ }^{3}$

When it comes to tailoring pill-taking women have never had so many options. So why should health care professionals advocate a change from the standard 21/7 regimen to one with a shorter or no hormone-free interval?

\section{BENEFITS OF TAILORED PILL REGIMENS}

Women benefit greatly from tailoring their COC use. Using a shortened hormone-free interval or continuous pill-taking regimen the pill can be used as a management strategy for gynaecological conditions such as endometriosis, ${ }^{4}$ dysmenorrhoea ${ }^{5}$ or premenstrual syndrome. ${ }^{6}$ These conditions often stabilise with continuous COC use, leading to considerably fewer symptomatic days and improved quality of life. Furthermore, extended regimens can benefit women who experience withdrawal symptoms during the hormone-free interval ${ }^{7} 8$ such as menstrual migraine, breast tenderness or acne. A Cochrane review commented that extended regimens are more effective than traditional regimens in managing withdrawal symptoms resulting in reduced frequency and severity. ${ }^{7}$ Alternatively women may simply wish not to have a bleed as frequently ${ }^{9} 10$ or to avoid bleeding for a particular event (e.g. a weekend away, holiday or sporting event).

Numerous studies have identified that extended COC use is safe, efficacious, results in decreased blood loss and is well tolerated. ${ }^{11-13}$ In relation to cycle control, potential users should be told that they will no longer have a regular 28-day cycle. There is a tendency to increased breakthrough bleeding and spotting, which is more pronounced in initial users (compared to previous COC users), ${ }^{10}$ but this generally improves over time, with episodes of amenorrhoea becoming more common. In a study looking at continuous use with Lybrel $(20 \mu \mathrm{g}$ EE and $90 \mu \mathrm{g}$ LNG) the authors reported amenorrhoea rates of $58.7 \%$ and an absence of bleeding (with or without spotting) in $79 \%$ of cases at Cycle $13 .{ }^{14}$ Wiegratz et al. $^{13}$ reviewed extended-cycle use (84/7) of Valette ${ }^{\circledR}$ (30 $\mu \mathrm{g} \mathrm{EE}$ and $2 \mathrm{mg}$ dienogest) compared to conventional use. They reported a relatively constant number of bleeding/spotting days with conventional use (16.5, 14.4, 14.7 and 17.7 days per 90-day reference period) while with extended-cycle use there was a gradual decline in the number of bleeding/spotting days (10.7, 8.1, 7.3 and 6.4 days per 90-day reference period). By the final 90 days of the study the extended cycle had 59\% (9.3 days) fewer bleeding days than the conventional group. Furthermore, while the number of intracyclic bleeding days is greater for the extended-use group throughout the study, there is a progressive decrease in intracyclic bleeding (6.9 days in Cycle 1 and 2.3 days in Cycle 4 compared to 1.5 days in Cycle 1 and 0.2 days in Cycle 4). ${ }^{13}$ It must be remembered that these studies have a fairly high dropout rate over time, which may skew the results towards reports of 'less bleeding and spotting'. One group have reported that co-administration of sub-antimicrobial-dose doxycyline during the initial phase of taking a continuous combined pill regimen may reduce breakthrough bleeding and the length of time needed to achieve amenorrhoea. ${ }^{15}$ However, for many women a flexible extended COC regimen would make more sense.

Importantly, clinicians can reassure women using a combined hormonal contraceptive preparation that having a monthly bleed is not necessary. Some new monthly preparations, such as Zoely $(1.5 \mathrm{mg}$ EE and $2.5 \mathrm{mg}$ nomegestrol acetate with 24 active and four placebo pills), report an absence of withdrawal bleeds with $22 \%$ of users having no bleeds at 4 months and $31 \%$ at 12 months. ${ }^{16}$ Modern progestogens such as nomegestrol acetate with high target receptor selectivity and progestational effects ${ }^{17}$ and preparations with continuous progestogen produce thin, decidualised endometrium with atrophied glands. The addition of an estrogen ensures endometrial stability. ${ }^{18}$

One way to increase patient acceptance is to adopt a woman-centred approach, advising continuous pill use until a bleed for 3-4 days occurs (providing 21 active pills have already been taken). At this point a 4-day pill-free interval should be taken. This approach has been built into Flexyess ${ }^{3}$ and facilitated by the Clyk device. Through ongoing continuous use of a particular pill women will often establish an individual duration of time between bleeds. ${ }^{19}$ This enables women to reduce the number of bleeds in a year and manipulate their cycle to avoid important events by stopping their pill early if their bleeding pattern would coincide with the event in question. In addition, research indicates that flexible regimens are associated with fewer bleeding days when compared to conventional use. Klipping et al. showed that women given the ability to flexibly manage their cycle had only 41 days of bleeding or spotting per year, while those using the pill conventionally had 65.8 days and those using a fixed extended regimen had 60.9 days. ${ }^{20}$

\section{WOMEN'S VIEWS}

A survey of German women, published in 2004, regarding attitudes to long-cycle $\mathrm{COC}$ reported that $37-46 \%$ wished to never bleed and $26-35 \%$ preferred a monthly bleed. Reasons cited for preferring a monthly bleed were concerns about long-term fertility and the view that a monthly bleed is natural. ${ }^{10}$ These concerns therefore must be discussed and addressed during method counselling. Menses returned to almost all women (94.7\%) within 60 days of stopping a continuous $\mathrm{COC},{ }^{21}$ and in a small study examining return of fertility after stopping the COC $81 \%$ of users had achieved a pregnancy within a year of discontinuing their COC. ${ }^{22}$ Furthermore, from studies 
examining changes in follicle-stimulating hormone and estradiol levels during the 7-day pill-free interval we know that levels increase quickly when exogenous hormones are withdrawn. ${ }^{23} 24$

Adequate counselling is key to women's acceptance of these new regimens. Very recent evidence suggests that adherence may be poor to 'off-licence' tailored regimens with patients finding instructions complex and difficult to follow. ${ }^{25}$ Others may not accept the inconvenience of unpredictable breakthrough bleeding or spotting. ${ }^{10}$ A number of women may still wish to see a monthly bleed but would prefer a lighter shorter bleed; in these circumstances a $24 / 4$ regimen may be their ideal choice.

\section{CLINICIANS' OPINIONS ON THE 'PROS AND CONS'}

As far back as 1977, clinicians were less enthusiastic about tailoring regimens than patients. ${ }^{1}$ At the time clinicians were concerned about irregular vaginal bleeding, that women might become pregnant without knowing, and that women might experience weight gain. Some $12 \%$ of the clinicians who took part in the original study disapproved of manipulation of the menstrual cycle to reduce the number of periods and 30\% expressed concern that a regular cycle would not be re-established once the tricycling stopped. ${ }^{1}$ Have clinician's attitudes changed greatly since then?

Clinicians' knowledge and attitudes to medically induced amenorrhoea and consequently extended-use contraception are important factors in prescribing these preparations. ${ }^{26} \mathrm{~A}$ recent survey of health care professionals attending educational conferences ${ }^{27}$ showed that while extended regimens are increasingly popular, those giving a monthly bleed are still the most frequently prescribed option. A review of prescribers in 2004 reported that patient request is the most common reason for prescribing extended regimens.

Clinicians may feel that discussing tailored COC regimens with women is complex and time consuming but when clear counselling is given it could be a perfect option. For others, continuous pill-taking with no breaks may be more suitable following an explanation that the breakthrough bleeding will settle in most cases. The availability of a licensed 'tailored product' such as Flexyess may encourage clinicians to modernise their practice, but in the few countries where this product has been launched initial sales have been slow. Prescribers, perhaps particularly those who are older, have been slow to grasp the advantages of the Clyk device and do not understand it well enough themselves to be confident in suggesting it to women. The solution may be to supply the device through pharmacists, who are more enthusiastic.

\section{CONCLUSIONS}

Extended contraceptive regimens are safe, efficacious and well tolerated by women yet they are rarely suggested by health care professionals. Tailoring their COC regimen should be an option available to all women, not only to those who ask for it or those with specific medical conditions. The 21/7 regimen was introduced to provide reassurance that the woman was not pregnant and to mimic nature, but women are demanding more in the 21 st century and we as health care professionals must respond to their demands. While counselling for tailored regimens may be more detailed than for traditional COC regimens, this should not hold us back in meeting the needs of women.

Competing interests Dr Mansour has received financial support to attend pharmaceutical advisory board meetings, undertake research studies, speak at educational meetings and conference along with travel grants from Astellas, Bayer, Consilient Healthcare, HRA Pharma, Merck, Pfizer and Vifor Pharma.

Provenance and peer review Commissioned; externally peer reviewed.

\section{REFERENCES}

1 Loudon NB, Foxwell M, Potts DM, et al. Acceptability of an oral contraceptive that reduces the frequency of menstruation: the tri-cycle pill regimen. $\mathrm{Br}$ Med J 1977;2:487-490.

2 Marks LV. Sexual Chemistry: A History of the Contraceptive Pill. New Haven, CT, USA: Yale University Press, 2010.

3 Medicines and Healthcare Products Regulatory Agency. Summary of Product Characteristics - Flexyess. 2013. http:// www.imb.ie/images/uploaded/swedocuments/LicenseSPC_ PA1410-065-001_11042013162158.pdf [accessed 8 July 2013].

4 Royal College of Obstetricians and Gynaecologists. The Investigation and Management of Endometriosis. Green-top Guideline No. 24. October 2006. http://www.rcog.org.uk/files/ rcog-corp/GTG2410022011.pdf [accessed 8 July 2013].

5 Strowitzki T, Kirsch B, Elliesen J. Efficacy of ethinylestradiol $20 \mu \mathrm{g} /$ drospirenone $3 \mathrm{mg}$ in a flexible extended regimen in women with moderate-to-severe primary dysmenorrohea: an open-label, multicentre, randomised, controlled study. J Fam Plann Reprod Health Care 2012;38:94-101.

6 Coffee AL, Kuehl TJ, Willis S, et al. Oral contraceptive and premenstrual syndrome: comparison of a 21/7 and extended regimen. Am J Obstet Gynecol 2006;195:1311-1319.

7 Edelman AB, Gallo MF, Jensen JT, et al. Continuous or extended cycle vs. cyclic use of combined oral contraceptives for contraception. Cochrane Database Syst Rev 2005;3:CD004695.

8 Coffee AL, Sulak PJ, Kuehl TJ. Long-term assessment of symptomatology and satisfaction of an extended oral contraceptive regimen. Contraception 2007;75:444-449.

9 den Tonkelaar I, Oddens BJ. Preferred frequency and characteristics of menstrual bleeding in relation to reproductive staus, oral contraceptive use and hormone replacement therapy use. Contraception 1999;59:357-362.

10 Wiegratz I, Hommel HH, Zimmermann T, et al. Attitude of German women and gynecologists towards long-cycle treatment with oral contraceptives. Contraception 2004;69:37-42.

11 Foidart JM, Sulak PJ, Schellschmidt I, et al. The use of an oral contraceptive containing ethinylestradiol and drospirenone in an extended regimen over 126 days. Contraception 2006;73:34-40.

12 Reif S, Snelder N, Blode H. Characterisation of the pharmacokinetics of ethinylestradiol and drospirenone in 
extended-cycle regimens: population pharmacokinetic analysis from a randomised phase III study. J Fam Plann Reprod Health Care 2013;39:e1.

13 Wiegratz I, Stahlberg S, Manthey T, et al. Effect of extended-cycle regimen with an oral contraceptive containing $30 \mathrm{mcg}$ ethinylestradiol and $2 \mathrm{mg}$ dienogest on bleeding patterns, safety, acceptance and contraceptive efficacy. Contraception 2011;84:133-143.

14 Archer DF, Jensen JT, Johnson JV, et al. Evaluation of a continuous regime of levonorgestrel/ethinyl estradiol: phase 3 study results. Contraception 2006;74:439-445.

15 Kaneshiro B, Edelman A, Carlson NE, et al. A randomized controlled trial of subantimicrobial-dose doxycycline to prevent unscheduled bleeding with continuous oral contraceptive pill use. Contraception 2012;85:351-358.

16 Mansour D, Verhoeven C, Sommer W, et al. Efficacy and tolerability of a monophasic combined oral contraceptive containing nomegestrol acetate and $17 \beta$-oestradiol in a $24 / 4$ regimen, in comparison to an oral contraceptive containing ethinylestradiol and drospirenone in a 21/7 regimen. Eur J Contracept Reprod Health Care 2011;16:430-443.

17 Sitruk-Ware R. New progestagens for contraceptive use. Hum Reprod Update 2006;12:169-178.

18 Wright KP, Johnson JV. Evaluation of extended and continuous oral contraceptive. Ther Clin Risk Manag 2008;4:905-911.

19 Szarewski A. Sisters doing it for themselves. J Fam Plann Reprod Health Care 2009;35:71-72.

20 Klipping C, Duijkers I, Fortier MP, et al. Contraceptive efficacy and tolerability of ethinylestradiol $20 \mu \mathrm{g} /$ drospirenone $3 \mathrm{mg}$ in a flexible extended regimen: an open label, multicentre, randomised, controlled study. J Fam Plann Reprod Health Care 2012;38:73-83.

21 Davis AR, Kroll R, Soltes B, et al. Occurrence of menses or pregnancy after cessation of continuous oral contraceptive. Fertil Steril 2008;89:1059-1063.

22 Barnhart K, Mirkin S, Grubb GS, et al. Return of fertility after cessation of continuous oral contraceptive. Fertil Steril 2009;91:1654-1656.

23 Schlaff WD, Lynch AM, Hughes HD, et al. Manipulation of pill-free interval in oral contraceptive pill users: the effect on ovarian suppression. Am J Obstet Gynecol 2004;190:943-949.

24 Willis SA, Kuehl TJ, Spiekerman AM, et al. Greater inhibition of the pituitary-ovarian axis in oral contraceptive regimens with a shortened hormone-free interval. Contraception 2006;74:100-103.

25 Weisberg E. Comparison of bleeding patterns between continuous twelve month use of a contraceptive vaginal ring and a low dose pill in a menstrually-signalled regimen. Oral presentation at the First Global Conference on Contraception, Reproductive and Sexual Health, 22-25 May 2013, Copenhagen, Denmark.

26 Frederick CE, Edelman A, Carlson NE, et al. Extended oral-contraceptives and medically induced amenorrhoea: attitudes, knowledge and prescribing habits of physicians. Contraception 2011;84:384-389.

27 Seval DL, Buckley T, Kuehl TJ, et al. Attitudes and prescribing patterns of extended-cycle oral contraceptives. Contraception 2011;84:71-75. 